\title{
ÍNDICE FUZZY DE CONFORTO TÉRMICO PARA FRANGOS DE CORTE
}

\author{
GUILHERME R. DO NASCIMENTO ${ }^{1}$, DANILO F. PEREIRA ${ }^{2}$, IRENILZA DE A. NÄÄS ${ }^{3}$, \\ LUIZ H. A. RODRIGUES ${ }^{4}$
}

\begin{abstract}
RESUMO: A estimativa de conforto térmico na avicultura moderna é importante para que sistemas de climatização possam ser acionados no tempo correto, diminuindo perdas e aumentando rendimentos. Embora a literatura corrente apresente alguns índices de conforto térmico, que são aplicados para essa estimativa, estes são baseados apenas em condições do ambiente térmico e não consideram fatores importantes inerentes aos animais, tais como genética e capacidade de aclimatação, provendo, geralmente, uma estimativa inadequada do conforto térmico das aves. Este trabalho desenvolveu o Índice Fuzzy de Conforto Térmico (IFCT), com o intuito de estimar o conforto térmico de frangos de corte, considerando que o mecanismo usado pelas aves para perda de calor em ambientes fora da zona termoneutra é a vasodilatação periférica, que aumenta a temperatura superficial, e que pode ser usada como indicador do estado de conforto. O IFCT foi desenvolvido a partir de dois experimentos, que proporcionaram 108 cenários ambientais diferentes. Foram usadas imagens termográficas infravermelhas, para o registro dos dados de temperaturas superficiais das penas e da pele, e o grau de empenamento das aves. Para os mesmos cenários de ambiente térmico observados nos experimentos, foram comparados os resultados obtidos usando o IFCT e o Índice de Temperatura e Umidade (ITU). Os resultados validaram o IFCT para a estimativa do conforto térmico de frangos de corte, sendo específico na estimativa de condições de perigo térmico, usual em alojamentos em países de clima tropical. Essa característica é desejável em modelos que estimem o bem-estar térmico de frangos de corte, pois situações classificadas como perigo acarretam no dispêndio de recursos para evitar perdas produtivas.
\end{abstract}

PALAVRAS-CHAVE: índice de conforto térmico, lógica Fuzzy, termografia infravermelho, zootecnia de precisão.

\section{THERMAL COMFORT FUZZY INDEX FOR BROILER CHICKENS}

\begin{abstract}
Estimating thermal comfort in modern poultry production is important that acclimatization systems can be triggered at appropriate time reducing losses and increasing yield. Although current literature presents some thermal comfort indexes which are applied for this estimation those are based just on ambient thermal conditions and do not consider important factors inherent to the animals such as genetics and capability of adaptation, generally providing an inadequate estimation of the birds' thermal comfort. This research developed the Fuzzy thermal comfort index (FTCI) aiming to estimate broilers' thermal comfort considering that the mechanism used by the birds for losing heat in environments outside the thermoneutral zone is the peripheral vasodilatation, which increases the surface temperature. Measurements of surface feathers and skin temperature of birds were used. The FTCI was developed using the data of two experiments which provided 108 distinct environmental scenarios. Infrared thermal images were used for registering surface temperature of feathers and skin, as well as the birds' feathering degree. For the same scenarios of thermal environment both FTCI and the temperature and humidity index (THI) were compared. Results validated the FTCI for estimating broilers' thermal comfort, being specific for the estimation of danger conditions usually found in housing in tropical climate countries. This characteristic is advantageous in models which estimate broiler thermal welfare, as occurrence classified as dangerous may lead to economical downward in avoiding productive losses.
\end{abstract}

KEYWORDS: thermal comfort index, fuzzy logic, infrared thermograph, precision livestock production.

\footnotetext{
${ }^{1}$ Zootecnista, Mestrando em Eng ${ }^{\text {a }}$ Agrícola, FEAGRI-UNICAMP, Campinas - SP, guilherme.nascimento@ feagri.unicamp.br.

${ }^{2}$ Eng $^{\circ}$ Agrícola, UNESP, Tupã - SP, danilo@ tupa.unesp.br.

${ }^{3}$ Eng $^{\mathrm{O}}$ Civil, FEAGRI-UNICAMP, Campinas - SP, irenilza@ feagri.unicamp.br.

${ }^{4}$ Eng ${ }^{0}$ Agrícola, FEAGRI-UNICAMP, Campinas - SP, lique@ feagri.unicamp.br.

Recebido pelo Conselho Editorial em: 21-7-2010

Aprovado pelo Conselho Editorial em: 6-2-2011
} 


\section{INTRODUÇÃO}

A evolução da avicultura resultou em um frango de corte precoce e com grande eficiência para converter diferentes alimentos em proteína animal. Apesar disso, uma série de problemas metabólicos e de manejo tem surgido, destacando-se entre eles o estresse calórico. A suscetibilidade das aves ao estresse calórico aumenta à medida que a umidade relativa e a temperatura ambiente ultrapassam a zona de conforto térmico, dificultando assim a dissipação de calor, incrementando consequentemente a temperatura corporal da ave, com efeito negativo sobre o desempenho (BORGES et al., 2003). Com a evolução da produção avícola no País, muitas instalações sofreram adaptações físicas para alcançar os índices de produtividade almejados pelos padrões da genética. Os avanços são múltiplos e caminham sempre em direção da melhora do conforto das aves. Segundo MOURA et al. (2006) e SANTOS et al. (2009), o conforto térmico no interior de instalações avícolas é fator de alta importância, pois condições inadequadas afetam consideravelmente a produção de frangos de corte.

Índices comumente utilizados para medir conforto térmico de frangos de corte, como índice de temperatura e umidade, não levam em consideração a evolução genética ocorrida na avicultura de corte. Com isso, o aumento na temperatura superficial pode servir como resposta fisiológica da ave a condições inadequadas de alojamento, como também o empenamento, que é uma resposta adaptativa ao ambiente e que influencia na perda de calor. A câmera de termografia infravermelha é uma técnica moderna, segura e não invasiva que permite a visualização do perfil de temperatura superficial de um objeto ou uma cena. Os dados obtidos por escaneamento de computador são processados e apresentados na forma de mapas de temperatura, que permitem uma detalhada análise da temperatura do campo (DENOIX, 1994; TESSIER et al., 2003).

A perda de calor para o ambiente está relacionada com a temperatura superficial da ave, que consiste em um somatório das contribuições ponderadas pela área de cada parte do corpo. RICHARDS (1971) considera a temperatura superficial (TS) de frangos de corte, com base na contribuição de cada parte da ave de acordo com os pesos $T S=0,03 T_{\text {crista }}+0,70 T_{\text {dorso }}+0,12 T_{\text {asa }}+0,06 T_{\text {cabegca }}+0,09 T_{\text {perna }}$.[eq.(1)]. Para DAHLKE et. al. (2005), a temperatura superficial média (TSM) da ave é representada pelos seguintes pesos $T S M=0,12 T_{\text {asa }}+0,03 T_{\text {cabega }}+0,15 T_{\text {perna }}+0,70 T_{\text {dorso }} \quad$ [eq.(2)]. Entretanto, ambos os trabalhos evidenciam que as partes cobertas com penas contribuem de maneira diferente à perda de calor que as partes de pele exposta.

FUKAYAMA et al. (2005) relataram o efeito do empenamento e da temperatura ambiente no desempenho zootécnico de aves e concluíram que a diminuição na cobertura de penas modifica a faixa de conforto térmico das aves, tornando-as mais adaptadas a altas temperaturas. CAHANER et al. (1995) demonstraram que o aumento de temperatura interna é maior em frangos de empenamento normal do que em frangos portadores do gene $\mathrm{Na}$ (pescoço pelado), devido ao seu menor empenamento.

A teoria dos conjuntos Fuzzy é uma ferramenta para tratar de incertezas, em casos nos quais há falta de informações. Tem sido aplicada em produção animal, gestão e controle ambiente de instalações zootécnicas (GATES et al., 2001; VRANKEN et al., 2005) e na estimativa de conforto e bem-estar de animais criados em sistemas intensivos (OLIVEIRA et al., 2005; OWADA et al., 2007; PEREIRA et al., 2008; PERISSINOTTO et al., 2009).

Diante dos desafios da avicultura industrial contemporânea, que precisa reduzir perdas produtivas decorrentes do ambiente térmico do ambiente de criação, este trabalho propõe um índice de conforto térmico para frangos de corte, baseado em lógica Fuzzy, que utiliza duas medidas de temperatura superficial das aves (temperatura das penas e temperatura da pele) e um escore de empenamento das aves, atribuído por um especialista. 


\section{MATERIAL E MÉTODOS}

O Índice Fuzzy de Conforto Térmico (IFCT) para frangos de corte foi desenvolvido à luz de teorias e experimentações referentes às perdas de calor da ave para o ambiente (YAHAV et al., 2004, 2005; TESSIER et al., 2003; SHINDER et al., 2007; CANGAR et al., 2008). Essas teorias e experimentações foram agrupadas neste trabalho em torno de três considerações: 1) a perda de calor para o ambiente está relacionada à temperatura superficial da ave, que consiste em um somatório das contribuições de cada parte do corpo, determinadas pela área de cada parte do corpo; 2) as áreas cobertas com penas dificultam a transferência de calor das aves para o ambiente, e sua temperatura superficial mantém forte correlação com a temperatura do ar, e 3) o grau de empenamento das aves, quando associado com a idade e a linhagem da ave, é um importante indicador de desempenho zootécnico.

\section{Experimentos}

Neste trabalho, foram reunidos dados de dois experimentos. O primeiro foi realizado a campo, e o outro, em ambiente controlado em câmara climática, no Laboratório de Conforto Ambiental da Faculdade de Engenharia Agrícola da UNICAMP, em Campinas - SP. Em ambos os experimentos, foram registradas a temperatura e a umidade relativa do ar com o Termo-higrômetro Tri-Sense ${ }^{\circledR}$ e a temperatura superficial das aves da linhagem Cobb $500^{\circledR}$ usando a câmera termográfica infravermelho TESTO $800^{\circledR}$. As temperaturas superficiais foram registradas em duas regiões das aves: temperatura das penas $(\mathrm{CP})$ e temperatura da pele (SP), conforme exemplo ilustrado na Figura 1.

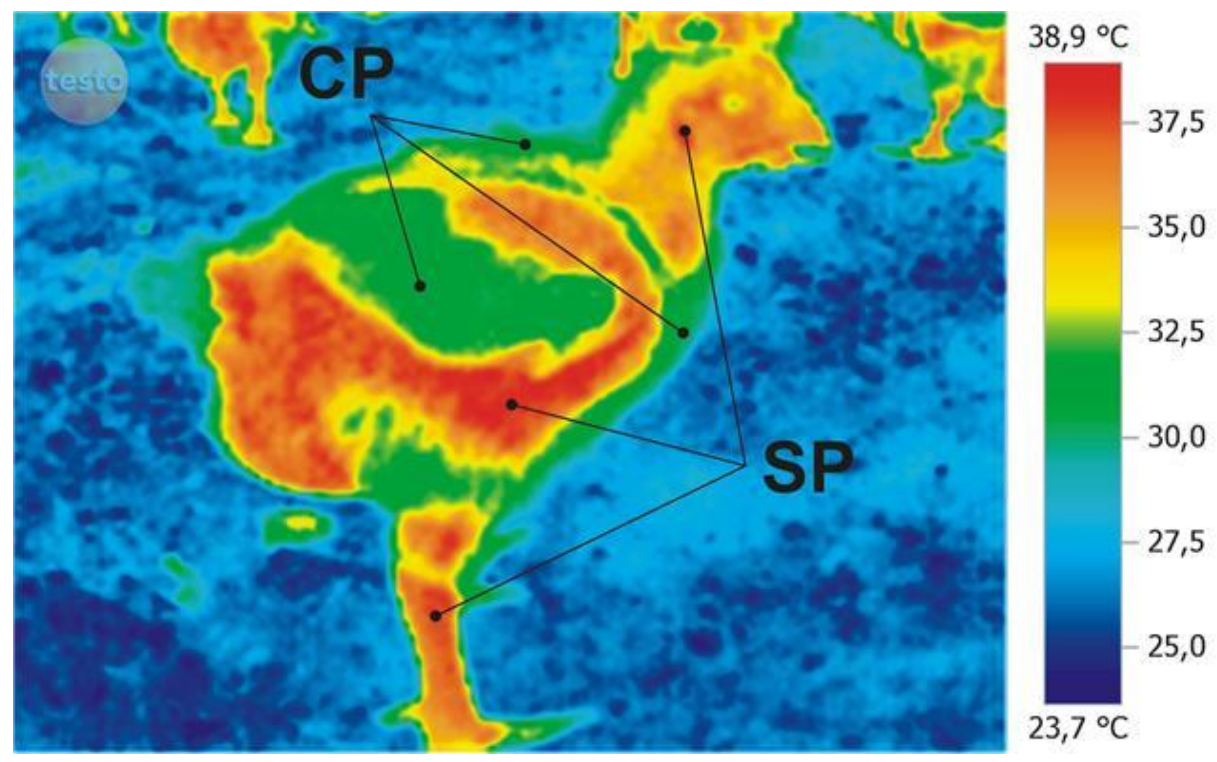

FIGURA 1. Imagem termográfica de uma ave com área da coleta das temperaturas superficiais de penas $(\mathrm{CP})$ e de pele (SP). Bird' thermographic image with the areas where the surface temperature was registered in the area with feathers $(\mathrm{CP})$, and in the skin (SP).

\section{Experimento 1}

Os dados deste experimento foram registrados em uma granja comercial localizada no município de Rio Claro, nas coordenadas $22^{\circ} 05^{\prime}$ e $22^{\circ} 40^{\prime} \mathrm{S}, 47^{\circ} 30^{\prime}$ e $47^{\circ} 55^{\prime} \mathrm{W}$, no Estado de São Paulo, no qual foram acompanhados dois lotes de produção de frangos de corte, em dois aviários próximos, sendo o primeiro lote no período de outubro e novembro de 2009 e o segundo no período de fevereiro e março de 2010. 
Cada aviário foi dividido em seis partes iguais ao longo do comprimento, em que se procedeu ao registro semanal da temperatura superficial das aves e da temperatura e umidade relativa do ar, caracterizando seis microambientes. Foram observadas 10 aves em cada uma das seis partes do aviário, com 14; 21; 28 e 35 dias de idade.

\section{Experimento 2}

O segundo experimento foi realizado em laboratório. Cinquenta aves foram criadas em aviário, em escala reduzida e distorcida, e, a cada semana, dez aves eram selecionadas aleatoriamente e acondicionadas na câmara climática. Após 30 minutos de exposição às temperaturas do ar de $18 ; 25$ e $32{ }^{\circ} \mathrm{C}$, foram capturadas as imagens termográficas das aves, com idades de $14 ; 21 ; 28$ e 35 dias.

\section{Procedimento experimental}

Considerando-se os dois experimentos, foram analisados 108 cenários ambientais diferentes, sendo 96 provenientes do Experimento 1 (Fatorial $2 \times 2 \times 6 \times 4=96$; dois lotes, dois aviários, seis ambientes por aviário e quatro idades) e 12 cenários provenientes do Experimento $2(3 \times 4=12$, três ambientes em quatro idades).

Para cada imagem termográfica de uma ave, foram registrados 10 pontos de temperatura das penas (CP) e dez pontos de temperatura da pele (SP), utilizando o software TESTO ${ }^{\circledR}(2009)$.

O grau de empenamento atribuído a cada imagem termográfica consistiu em um escore categórico, atribuído por um técnico especializado, no momento da estimativa do conforto térmico, considerando-se o empenamento esperado para a linhagem e a idade da ave. Este escore é fundamentado na experiência do tratador e carrega informações referentes ao histórico de criação das aves, inferindo o grau de adaptação dessas aves ao ambiente térmico de criação. Desta forma, foram estabelecidas três variáveis de entrada para o IFCT: temperatura superficial das penas, temperatura superficial da pele e grau de empenamento.

O Índice Fuzzy de Conforto Térmico foi desenvolvido em ambiente MATLAB ${ }^{\circledR}$ 6.1, usando o toolbox Fuzzy. Foi utilizado o método de Mamdani, e as transformações dos resultados Fuzzy em valor numérico foram obtidas pela defuzzificação, pelo método do centro de área (COA), em que o centro da área de saída é o centro de gravidade da função de distribuição de possibilidade da ação de controle (AMENDOLA et al., 2004; BARROS \& BASSANEZI, 2006).

Realizou-se uma análise de correlação linear de Pearson entre as variáveis de ambiente e as temperaturas das regiões de penas e de pele, para quantificar a dependência entre as variáveis. A partir dos dados de temperaturas superficiais coletadas nas imagens termográficas, foi realizada uma análise estatística descritiva, verificando-se a normalidade das distribuições desses dados e as medidas de posição (quartis), que foram utilizados para descrever as funções de pertinência destas variáveis de entrada, divididas em três conjuntos Fuzzy: baixo, médio e alto, utilizando funções trapezoidais e triangulares.

A escala de escore para o empenamento variou de 0 a 5, divididos em três conjuntos Fuzzy: baixo, médio e alto, utilizando funções trapezoidais e triangulares. Para a função de pertinência da variável resposta 'conforto térmico', foram definidos três conjuntos Fuzzy, distribuídos simetricamente no domínio: conforto, alerta e perigo, utilizando apenas funções triangulares. Os resultados obtidos com o Índice Fuzzy de Conforto Térmico (IFCT) foram verificados utilizando os valores do Índice de Temperatura e Umidade (ITU), por meio da eq.(1), proposta por THOM (1959) e citada por CARVALHO et al. (2009), calculados para os 108 cenários observados nos experimentos. O ITU foi classificado em Conforto (entre 64 e 74), Alerta (entre 74 e 78 ) e Perigo entre 78 e 84.

$$
I T U=T b s+0,36 T p o+41,5
$$


em que,

ITU - índice de temperatura e umidade;

Tbs - temperatura de bulbo seco, ${ }^{\circ} \mathrm{C}$, e

Tpo - temperatura de ponto de orvalho, ${ }^{\circ} \mathrm{C}$.

A avaliação do modelo foi feita com as medidas de sensibilidade [eq.(2)], especificidade [eq.(3)], valor preditivo positivo (VPP) e valor preditivo negativo (VPN) para cada condição [eq.(4)]. Posteriormente, esses valores foram usados para construir a curva ROC (Receiver Operating Characteristics) do IFCT.

em que,

$$
\begin{aligned}
& \text { Sensibilidade }=\operatorname{Prob}\left(\frac{I F C T_{\text {positivo }}}{I T U_{\text {positivo }}}\right) \\
& \text { Especificidade }=\operatorname{Prob}\left(\frac{I F C T_{\text {negativo }}}{I T U_{\text {negativo }}}\right) \\
& V P P=\operatorname{Prob}\left(\frac{I T U_{\text {positivo }}}{I F C T_{\text {positivo }}}\right)
\end{aligned}
$$

A sensibilidade é a medida do percentual de ITU para cada uma das condições positivas de conforto, alerta e perigo, que foram também detectados positivamente pelo IFCT (ITU positivo $\mathrm{e}$

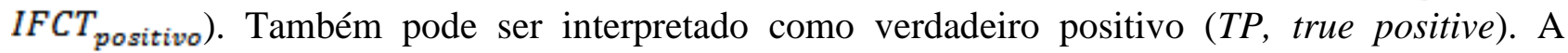
especificidade é a medida do ITU para cada uma das condições negativas de conforto, alerta e perigo, que também foram detectadas negativamente pelo IFCT (ITU $U_{\text {negativo }}$ e $I F C T_{\text {negativo }}$ ). O complemento dessa medida também é interpretado como falso positivo ( $F P$, false positive). $\mathrm{O}$ valor preditivo mede a probabilidade de IFCT classificar positivamente (VPP) a ocorrência de conforto, alerta ou perigo, e o resultado coincidir com o classificado pelo ITU.

\section{RESULTADOS E DISCUSSÃO}

O teste de correlação linear de Pearson, aplicado nos dados obtidos nos experimentos, mostrou que a temperatura superficial das penas (CP) apresentou alta correlação linear com a temperatura do ar ( $\mathrm{p}<0,01 ; \mathrm{r}=0,814)$ e com o ITU $(\mathrm{p}<0,01 ; \mathrm{r}=0,819)$. A temperatura do ar ambiente, monitorada nos experimentos, foi superior a $27{ }^{\circ} \mathrm{C} \mathrm{em} 75 \%$ dos casos (Tabela 1), o que corrobora CAHANER et al. (1995), que encontraram que a temperatura das penas se correlaciona com a temperatura corporal de frangos de corte em altas temperaturas ambientais.

TABELA 1. Estatística descritiva das temperaturas superficial de penas e de pele e das variáveis ambientais. Descriptive statistics of the surface temperatures of the feathers and skin, and the environmental variables.

\begin{tabular}{lccccccc}
\hline & Mínimo & Q1 & Mediana & Q3 & Máximo & Média & $\sigma$ \\
\hline CP $\left({ }^{\circ} \mathrm{C}\right)$ & 16,6 & 30,1 & 31,4 & 32,5 & 39,2 & 30,84 & 2,78 \\
SP $\left({ }^{\circ} \mathrm{C}\right)$ & 29,0 & 36,5 & 37,6 & 38,3 & 40,6 & 37,28 & 1,54 \\
Tar $\left({ }^{\circ} \mathrm{C}\right)$ & 18,0 & 27,0 & 28,6 & 30,3 & 34,3 & 27,96 & 3,89 \\
UR $(\%)$ & 46,0 & 61,0 & 65,0 & 68,0 & 76,0 & 64,44 & 6,56 \\
ITU & 64,4 & 75,6 & 77,7 & 79,8 & 83,4 & 76,84 & 4,79 \\
\hline
\end{tabular}

CP - temperatura superficial das aves em regiões cobertas com penas; SP - temperatura superficial das aves em regiões não cobertas com penas; Tar - temperatura do ar; UR - umidade relativa do ar; ITU - índice de temperatura de umidade relativa do ar (autor); Q1 valor do primeiro quartil; Q3 - valor do terceiro quartil; $\sigma$ - desvio-padrão da distribuição. 
Devido às altas temperaturas e às altas umidades relativas observadas dentro dos aviários no Brasil, o organismo das aves tem dificuldade em transferir calor para o ambiente, e elas expressam isto no seu comportamento, cujo resultado final é a redução da produção. As dificuldades em perder calor para o ambiente podem ser medidas na pequena variação de temperatura entre a superfície da ave e o ar que a envolve (YAHAV et al. 2005). Portanto, a temperatura superficial elevada da ave pode indicar que ela está com dificuldade de perder calor e, provavelmente, indicando estresse por calor. Pesquisas comprovam que o aumento da temperatura corporal das aves está relacionado à elevação da temperatura ambiente (WELKER et al., 2008).

Segundo DAHLKE et al. (2005), frangos de linhagens comerciais de rápido crescimento apresentam menor tolerância ao calor, devido a um aumento da temperatura corporal interna, quando criados em ambiente quente.

Pelo teste de normalidade de Kolmogorov-Smirnov, as variáveis temperatura superficial das penas (CP) e temperatura superficial da pele (SP) não apresentaram distribuição normal $(\mathrm{p}<0,001)$. Verificaram-se, através da estatística descritiva das variáveis ambientais, os domínios de valores de cada variável (Tabela 1) válidos para o IFCT.

As funções de pertinência das variáveis de temperatura superficial das penas e temperatura da pele das aves foram elaboradas a partir das medidas de posição das funções de distribuição dessas variáveis obtidas nos dados experimentais (Figura 2).
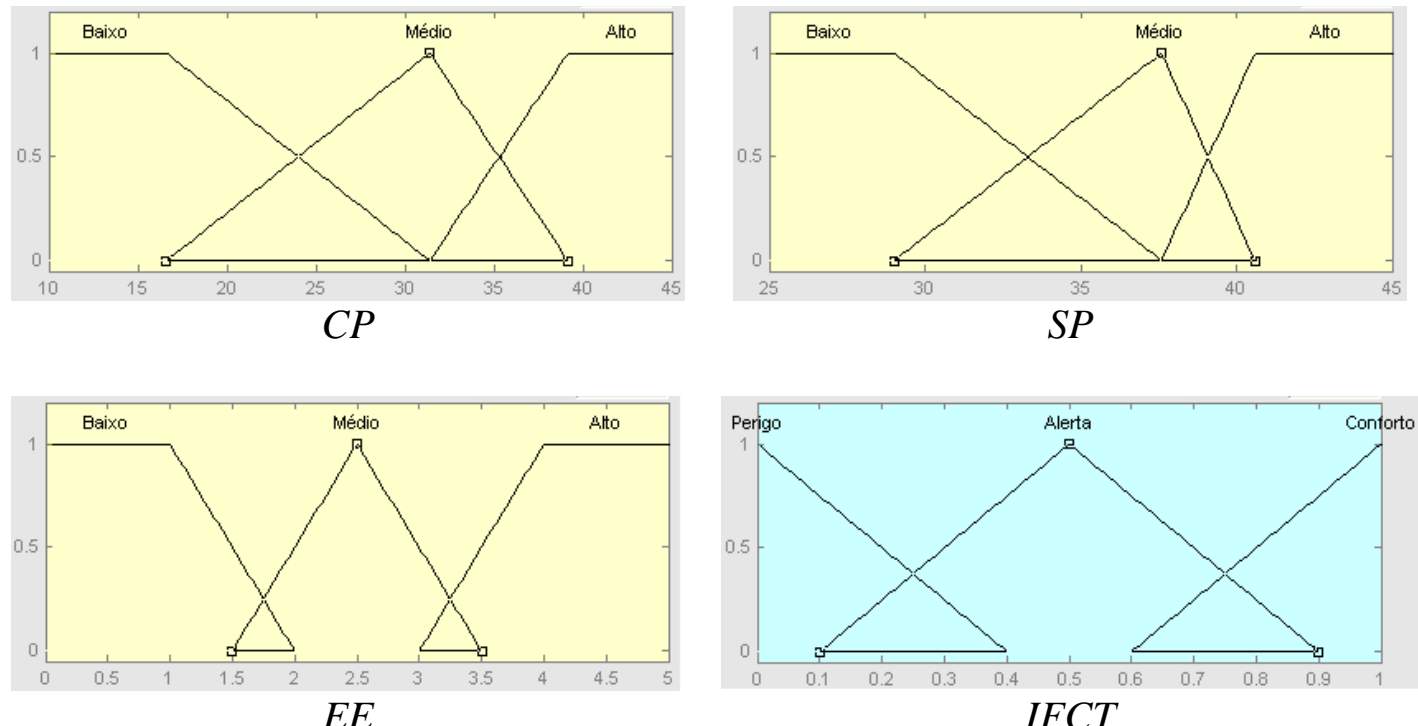

FIGURA 2. Funções de pertinência das variáveis independentes temperaturas de penas (CP) e de pele (SP) e escore de empenamento (EE), e da variável dependente (matriz demanda) Índice Fuzzy de Conforto Térmico (IFCT). Membership functions of the independent variables temperature of feathers (CP) and skin (SP) and Feathering score (EE), and the dependent variable (demand matrix) Fuzzy Thermal Comfort Index (IFCT).

A partir das classificações feitas nas funções de pertinência das temperaturas superficiais de penas e de pele, aplicou-se o teste não paramétrico de Kruskal-Wallis, para verificar diferenças significativas de temperatura superficial entre essas classes. Os resultados mostraram que, tanto para a temperatura superficial coberta com penas $(\mathrm{CP})$, como para a temperatura superficial da pele (SP), houve diferenças significativas entre todas as classes $(\mathrm{p}<0,01)$, conforme indica a Figura 3. A construção das regras do sistema Fuzzy (Tabela 2) corresponde à metodologia tradicional de construção de modelos Fuzzy (AMENDOLA et al., 2004; AMENDOLA \& SOUZA, 2004). 


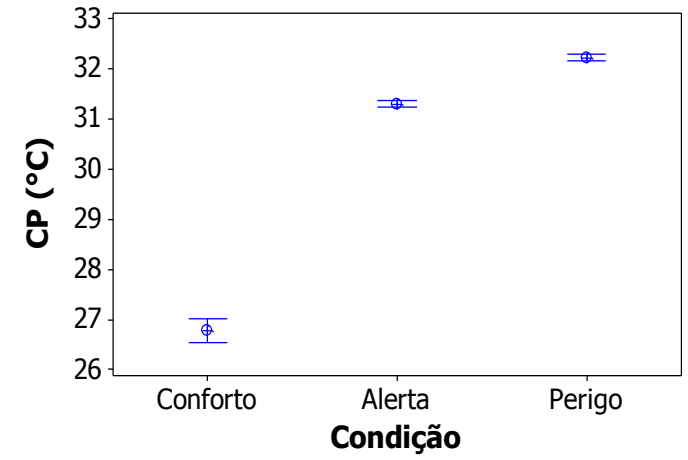

(a)

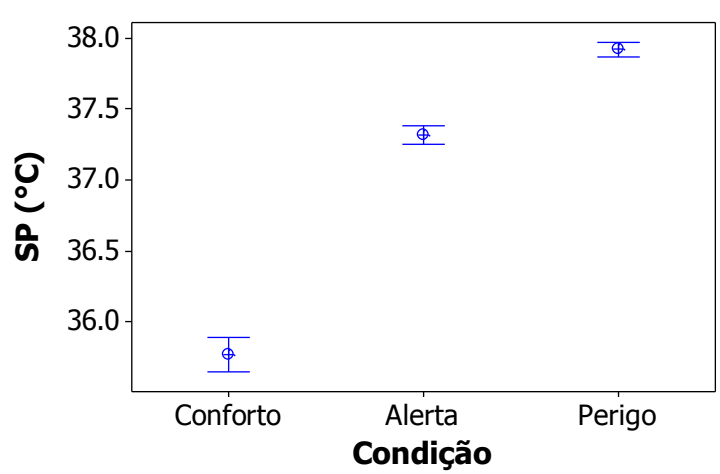

(b)

FIGURA 3. Gráficos de intervalos de confiança a 95\% para as variáveis de temperatura superficial da pele (SP, a) e temperatura superficial das penas (CP, b). Charts of confidence intervals at $95 \%$ for the variables of skin surface temperature $(\mathrm{SP}$,$) and surface$ temperature of feather $(\mathrm{CP}, \mathrm{b})$.

TABELA 2. Classificação de conforto térmico em função das variáveis preditoras. Thermal comfort rating according to the predicted variables.

\begin{tabular}{|c|c|c|c|c|}
\hline Regra & $\begin{array}{c}\text { Temp. Superficial } \\
\text { das Penas }\end{array}$ & $\begin{array}{l}\text { Temp. Superficial da } \\
\text { Pele }\end{array}$ & Empenamento & $\begin{array}{c}\text { Conforto Térmico } \\
\text { (peso) }\end{array}$ \\
\hline 1 & Alta & Alta & Alta & Perigo $(1,0)$ \\
\hline 2 & Alta & Alta & Média & Perigo $(0,75)$ \\
\hline 3 & Alta & Alta & Baixa & Perigo $(0,5)$ \\
\hline 4 & Alta & Média & Alta & Perigo $(0,5)$ \\
\hline 5 & Alta & Média & Média & Alerta $(1,0)$ \\
\hline 6 & Alta & Média & Baixa & Alerta $(0,75)$ \\
\hline 7 & Alta & Baixa & Alta & Alerta $(0,75)$ \\
\hline 8 & Alta & Baixa & Média & Alerta $(0,5)$ \\
\hline 9 & Alta & Baixa & Baixa & Conforto $(0,5)$ \\
\hline 10 & Média & Alta & Alta & Perigo $(1,0)$ \\
\hline 11 & Média & Alta & Média & Perigo $(0,5)$ \\
\hline 12 & Média & Alta & Baixa & Alerta $(1,0)$ \\
\hline 13 & Média & Média & Alta & Alerta $(0,75)$ \\
\hline 14 & Média & Média & Média & Conforto $(0,5)$ \\
\hline 15 & Média & Média & Baixa & Conforto $(0,75)$ \\
\hline 16 & Média & Baixa & Alta & Alerta $(0,5)$ \\
\hline 17 & Média & Baixa & Média & Conforto $(0,75)$ \\
\hline 18 & Média & Baixa & Baixa & Conforto $(1,0)$ \\
\hline 19 & Baixa & Alta & Alta & Alerta $(1,0)$ \\
\hline 20 & Baixa & Alta & Média & Alerta $(0,75)$ \\
\hline 21 & Baixa & Alta & Baixa & Alerta $(0,5)$ \\
\hline 22 & Baixa & Média & Alta & Conforto $(0,75)$ \\
\hline 23 & Baixa & Média & Média & Conforto $(1,0)$ \\
\hline 24 & Baixa & Média & Baixa & Conforto $(0,75)$ \\
\hline 25 & Baixa & Baixa & Alta & Conforto $(1,0)$ \\
\hline 26 & Baixa & Baixa & Média & Conforto $(0,75)$ \\
\hline 27 & Baixa & Baixa & Baixa & Conforto $(0,5)$ \\
\hline
\end{tabular}


Os pesos estabelecidos para cada regra foram inferidos por um especialista que identificava o grau de verdade inerente a cada regra. Esse tipo de atribuição de pesos é possível fazer em modelos matemáticos Fuzzy, uma vez que, teoricamente, esses modelos trabalham com graus de pertinência, ou grau de verdade, ao analisar se um determinado dado pertence a um conjunto Fuzzy (BARROS \& BASSANEZI, 2006).
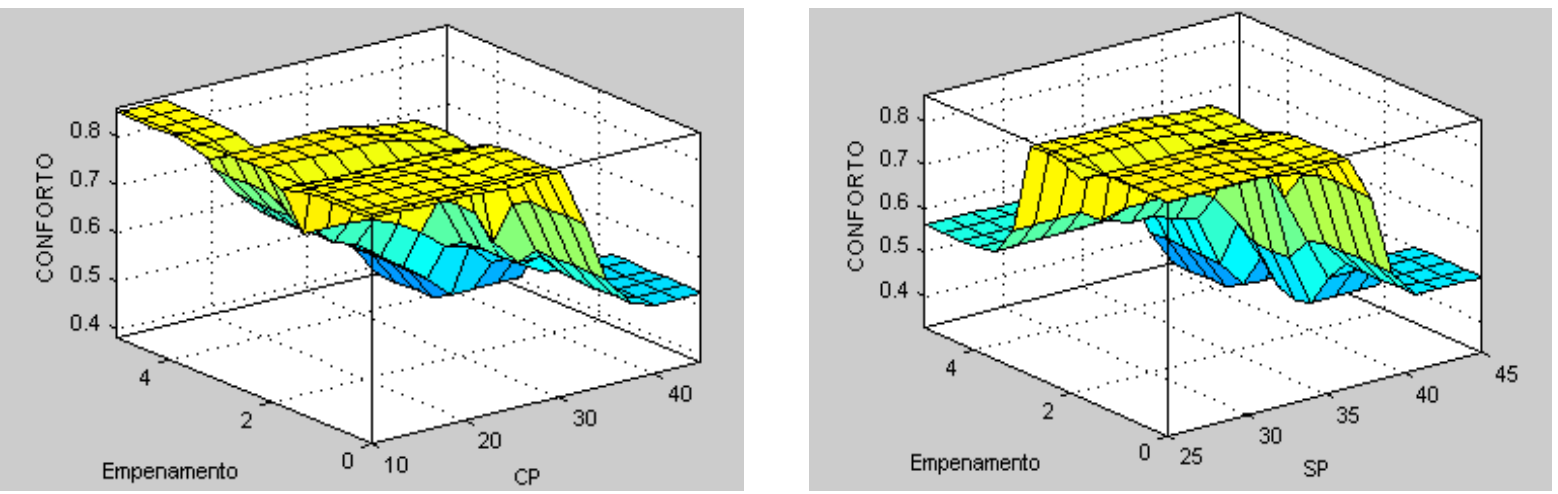

FIGURA 4. Gráfico de superfície das temperaturas superficiais das áreas cobertas com penas (CP) e não cobertas com penas (SP), em relação ao grau de empenamento. Graph of surface temperatures of the skin surface areas covered with feathers (CP) and not covered with feathers (SP), in relation to the degree of feathering.

As medidas para validação do IFCT estão representadas na Tabela 3, para os graus de empenamento categóricos baixo, médio e alto, definidos na função de pertinência (Figura 2).

TABELA 3. Sensibilidade, especificidade e valor preditivo positivo (VPP) do IFCT (Índice Fuzzy de Conforto Térmico) em relação ao ITU (Índice de Temperatura e Umidade) nas três classes de empenamento. Sensitivity, specificity and predicted value (VPP) of the IFCT Index (Fuzzy Thermal Comfort Index) in relation to THI (Temperature and Humidity Index) in the three classes of feathering.

\begin{tabular}{ccccc}
\hline IFCT & Empenamento & Sensibilidade & Especificidade & VPP \\
\hline \multirow{3}{*}{ Conforto } & Baixo & 0,98 & 0,87 & 0,65 \\
& Médio & 0,96 & 0,75 & 0,48 \\
& Alto & 0,98 & 0,93 & 0,77 \\
\hline \multirow{3}{*}{ Alerta } & Baixo & 0,97 & 0,80 & 0,74 \\
& Médio & 0,96 & 0,97 & 0,95 \\
& Alto & 0,96 & 0,84 & 0,78 \\
\hline \multirow{3}{*}{ Perigo } & Baixo & 0,50 & 0,98 & 0,98 \\
& Médio & 0,52 & 0,97 & 0,99 \\
& Alto & 0,65 & 0,97 & 0,98 \\
\hline
\end{tabular}

A medida de sensibilidade, que mede a probabilidade de acertos do IFCT em relação à condição real definida pelo ITU, variou de 96 a 98\% para as condições de conforto e de alerta, e de $56 \%$, em média, para a condição de perigo, nas três classes de empenamento. A menor sensibilidade para a condição de perigo indica que a ave está mais adaptada ao ambiente mais próximo ao extremo de calor, que é classificado como perigo pelo ITU, pela variação na temperatura superficial determinada pelo IFCT (LIN et al., 2006). A partir dos valores de sensibilidade e especificidade (Tabela 3), construiu-se a curva ROC do IFCT (Figura 5). 


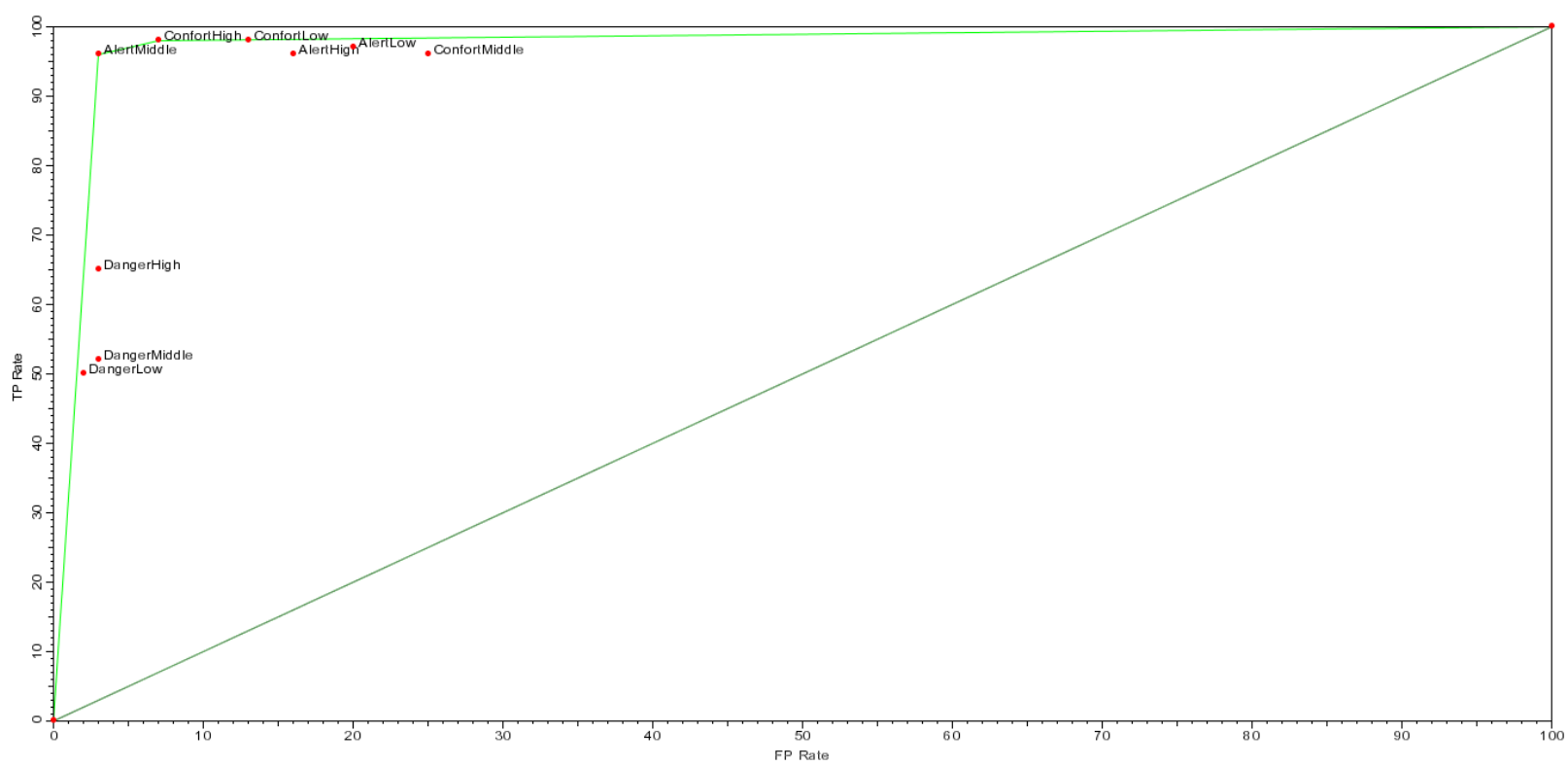

FIGURA 5. Curva ROC do Índice Fuzzy de Conforto Térmico para frangos de corte, em que Comfort, Alert e Danger correspondem às classes de conforto térmico a que as aves estão submetidas, e High, Middle e Low correspondem à classe de empenamento das aves. ROC curve of Fuzzy Index of Thermal Comfort for broilers, where Comfort, Alert and Danger are the classes of thermal comfort that birds are subject, and High, Middle and Low are the class of feather covering.

Na curva ROC (Figura 5), valores de FP Rate próximos a zero correspondem à alta especificidade (próximo de 100\%), ou seja, o modelo avaliado tem alto índice de acertos quando classifica os dados nessa região. Valores de TP Rate próximos a 100\% significam alta sensibilidade do modelo, que tende a posicionar os valores com maior frequência nessas classes.

As classes de perigo para todos os graus de empenamento definidos ficaram posicionadas na curva ROC, em região com alta especificidade e baixa sensibilidade. Isso significa que o IFCT não classifica com frequência os valores nessas classes (baixa sensibilidade), mas, quando o faz, tem alto índice de acerto (alta especificidade). Essa característica é muito interessante, pois espera-se que o modelo acerte nessas condições, uma vez que serão determinantes para as ações corretivas no aviário e, portanto, com dispêndio de recursos econômicos (BORGES et al., 2003; MOURA et al., 2006; SANTOS et al., 2009). As demais condições estão posicionadas na curva ROC em região com alta sensibilidade e alta especificidade, validando o modelo IFCT. A maior sensibilidade para as condições de conforto e alerta indica que o IFCT tende a classificar as aves como mais tolerantes ao calor que o ITU, corroborando PEREIRA \& NÄ̈̈S (2008), YAHAV et al. (2004) e YAHAV et al. (2005). Essa característica do modelo pode ser justificada por considerar o empenamento, que é uma medida de adaptação das aves (CAHANER et al., 1995; FUKAYAMA et al., 2005).

As temperaturas superficiais de penas e pele podem ser obtidas a partir de sensores de infravermelho, que hoje são comumente encontrados nas granjas de produção, possibilitando o uso do IFCT em granjas comerciais para estimar o conforto térmico de frangos de corte em tempo real.

\section{CONCLUSÃO}

O Índice Fuzzy de Conforto Térmico (IFCT) permitiu estimar as condições de conforto, alerta e perigo do conforto térmico de frangos de corte alojados em condições tropicais, sendo específico na estimativa de condições de perigo térmico. Essa característica é desejável em modelos que estimem o bem-estar térmico de frangos de corte, pois situações classificadas como perigo acarretam no dispêndio de recursos econômicos para evitar perdas produtivas. 


\section{REFERÊNCIAS}

AMENDOLA, M.; CASTANHO, M.J.; NÄÄS, I.A.; SOUZA, A.L. Análise matemática de condições de conforto térmico para avicultura usando a teoria dos conjuntos Fuzzy. Biomatemática, Campinas, v.14, p.87-92, 2004.

AMENDOLA, M.; SOUZA, A. Manual do uso da teoria dos conjuntos Fuzzy no MATLAB 6.5. Campinas: CPG/FEAGRI/UNICAMP, 2004. 30 p.

BARROS, L.C.; BASSANEZI, R.C. Tópicos de Lógica Fuzzy e Biomatemática. Campinas: IMECC-UNICAMP, 2006. 354 p.

BORGES, S.A.; MAIORKA, A.; SILVA, A.V.F. Heat stress physiology and electrolytes for broilers. Ciência Rural, Santa Maria, v.33, n.5, p.975-981, 2003.

CAHANER, A.; PINCHASOV, Y.; NIR, I. Effect of dietary protein under high ambient temperature on body weight, breast meat yield and abdominal fat deposition, of broiler stock differing in growth rate and fatness. Poultry Science, Champaign, v.74, n.6, p.968-975, 1995.

CANGAR, O.; AERTS, J.M.; BUYSE, J.; BERCKMANS, D. Quantification of the spatial distribution of surface temperatures of broilers. Poultry Science, Champaign, v.87, n.12, p.2.4932.499, 2008.

CARVALHO, V.F.; JÚNIOR, T.Y.; FERREIRA, L.; DAMASCENO, F.A.; SILVA, M.P. Mapping of potential use of evaporative cooling systems in Southeastern Brazil. Revista Brasileira de Engenharia Agrícola e Ambiental, Campina Grande, v.13, n.3, p.358-366, 2009.

DAHLKE, F.; GONZALES, E.; GADELHA, A.C.; MAIORKA, A.; BORGES, S.A.; ROSA, P.S.; FILHO, D.E.F.; FURLAN, R.L. Feathering, triodothyronine and thyroxine plasma levels and body temperature of two broiler lines raised under different temperatures. Ciência Rural, Santa Maria, v.35, n.3, p.664-670, 2005.

DENOIX, J.M. Diagnostic techniques for identification and documentation of tendon and ligament injuries. Veterinary Clinics of North America: Equine Practice, Maryland Heights, v.10, n.2, p.365407, 1994.

FUKAYAMA, E.H.; SAKOMURA, N.K.; NEME, R.; FREITAS, E.R. Effect of environmental temperature and feather coverage on the performance of two laying-type pullets lines. Ciência Agrotecnologia, Lavras, v.29, n.6, p.1.272-1.280, 2005.

GATES, R.S.; CHAO, K.; SIGRIMIS, N. Identifying design parameters for fuzzy control of staged ventilation control systems. Computers and Electronics in Agriculture, Bornsesteeg, v.31, p.61-74, 2001.

LIN, H.; JIAO, H.C.; BUYSE, J.; DECUYPERE, E. Strategies for preventing heat stress in poultry. World's Poultry Science Journal, Beekbergen, v.62, n.1, p.71-86, 2006.

MOURA, D.J.; NÄÄS, I.A.; PEREIRA, D.F.; SILVA, R.B.T.R.; CAMARGO, G.A. Animal welfare concepts and strategy for poultry production: a review. Revista Brasileira de Ciência Avícola, Campinas, v.8, n.1, p.137-148, 2006.

OLIVEIRA, L.H.; AMENDOLA, M.; NÄÄS, I.A. Estimativa das condições de conforto térmico para avicultura de postura usando a teoria dos conjuntos Fuzzy. Engenharia Agrícola, Jaboticabal, v.25, n.2, p.300-307, 2005.

OWADA, A.N.; NÄÄS, I.A.; MOURA, D.J.; BARACHO, M.S. Estimativa de bem-estar de frango de corte em função da concentração de amônia e grau de luminosidade no galpão de produção.

Engenharia Agrícola, Jaboticabal, v.27, n.3, p.611-618, 2007. 
PEREIRA, D.F.; BIGHI, C.A.; GABRIEL FILHO, L.R.A.; GABRIEL, C.P.C. Sistema fuzzy para estimativa do bem-estar de matrizes pesadas. Engenharia Agrícola, Jaboticabal, v.28, n.4, p.624633, 2008.

PEREIRA, D.F.; NÄÄS, I.A. Estimating the thermoneutral zone for broiler breeders using behavioral analysis. Computers and Electronics in Agriculture, Davis, v.62, n.1, p.2-7, 2008.

PERISSINOTO, M.; MOURA, D.J.; CRUZ, V.F.; SOUZA, S.R.L.; LIMA, K.A.O.; MENDES, A.S. Thermal comfort on Subtropical and Mediterranean climate analyzing some physiological data through fuzzy theory. Ciência Rural, Santa Maria, v.39, n.5, p.1.492-1.498, 2009.

RICHARDS, S.A. The significance of changes in the temperature of the skin and body core of the chicken in the regulation of heat loss. The Journal of Physiology, Londres, v.216, n.1, p.1-10, 1971.

SANTOS, P.A.; BAÊTA, F.C.; TINÔCO, I.F.F.; ALBINO, L.F.T.; CECON, P.R. Ventilação em modos túnel e lateral em galpões avícolas e seus efeitos no conforto térmico, na qualidade do ar e no desempenho das aves. Revista CERES, Viçosa-MG, v.56, n.2, p.172-180, 2009.

SHINDER, D.; RUSAL, M.; TANNY, J.; DRUYAN, S.; YAHAV, S. Thermoregulatory responses of chicks (Gallus Domesticus) to low ambient temperatures at an early age. Poultry Science, Champaign, v.86, n.10, p.2.200-2.209, 2007.

TESSIER, M.; TREMBLAY, D.D.; KLOPFENSTEIN, C.; BEAUCHAMP, G.; BOULIANNE, M. Abdominal skin temperature variation in healthy broiler chickens as determined by thermography. Poultry Science, Champaign, v.82, n.5, p.846-849, 2003.

TESTO. Software TEXTO, versão 1.4. Disponível em: www.testo.com. Acesso em: 20 abr. 2010.

THOM, E.C. The discomfort index. Weatherwise, Omaha, v.12, n.1, p.57-60, 1959.

VRANKEN, E.; GEVERS, R.; AERTS, J.M.; BERCKMANS, D. Performance of model-based predictive control of the ventilation rate with axial fans. Biosystems Engineering, Maryland Heights, v.91, n.1, p.81-98. 2005.

WELKER, J.S.; ROSA, A.P.; MOURA, D.J.; MACHADO, L.P.; CATELAN, F.; UTTPATEL, R. Temperatura corporal de frangos de corte em diferentes sistemas de climatização. Brazilian Journal of Animal Science, Viçosa-MG, v.37, n.8, p.1.463-1.467, 2008.

YAHAV, S.; SHINDER, D.; TANNY, J.; COHEN, S. Sensible heat loss: the broiler's paradox. World's Poultry Science Journal, Beekbergen, v.61, n.3, p.419-434, 2005.

YAHAV, S.; STRASCHNOW, A.; LUGER, D.; SHINDER, D.; TANNY, J.; COHEN, S. Ventilation, sensible heat loss, broiler energy, and water balance under harsh environmental conditions. Poultry Science, Champaign, v.83, n.2, 253-258, 2004. 